\title{
Prolactin Secreting Pituitary Carcinoma with Extracranial Spread Presenting with Pathological Fracture of Femur
}

Sir,

Pituitary carcinoma is considered as extremely rare neoplasm and account for $0.1 \%-0.2 \%$ pituitary neoplasm. ${ }^{[1]}$ Pituitary carcinoma carry very poor prognosis. For confirmation of the diagnosis of pituitary carcinoma, require radiological as well histopathological demonstration of the presence of metastases. Pituitary carcinoma may develop due to malignant transformation of preexisting functional hormone secreting benign pituitary adenoma after a varying period of latency, which may extend up to many years after the initial diagnosis ranging from few months to many years. Present with extracranial metastasis. Authors report an interesting case with invasive prolactinoma, who presented with pathological fracture of femur. She underwent surgical management.

Elderly female patient present with a clinical history of progressive swelling and pain with inability to wear weight on lower limbs for the past 4 days. She was a known and diagnosed case of prolactinoma since 2007, magnetic resonance imaging (MRI) brain at previous admission had revealed the presence of pituitary microadenoma of with high serum prolactin (PRL) level and underwent transsphenoidal surgical decompression of pituitary adenoma and also advised medical treatment with dopamine agonist in the follow-up period. She was brought to emergency services at current admission. On neurological examination, she had bitemporal hemianopsia. The serum PRL concentration was $1200 \mathrm{mg} / \mathrm{l}$ (normal value $<22 \mathrm{mg} / \mathrm{l}$ ), where brain computed tomography scan was carried out and revealed the presence of hyperdense mass lesion in sella with extrasellar spread [Figure 1]. MRI brain with sella showed a presence of a sellar mass

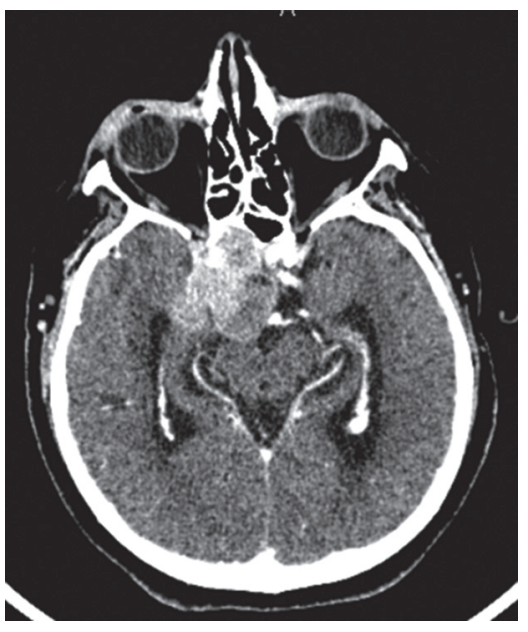

Figure 1: Brain computed tomography scan was carried out and revealed the presence of hyperdense mass lesion in sella with extrasellar spread

measuring about of $3.5 \mathrm{~cm}$ and extending into the right sphenoidal sinus as well as the cavernous sinus and causing compression the adjacent temporal lobes; MRI of the muscle was present, with diaphyseal metastatic lesion [Figure 2a and $\mathrm{b}$ ]. The biopsy was suggestive of metastatic deposit of PRL secreting pituitary carcinoma [Figure 3]. The patient was referred to oncological management.

Pituitary carcinomas are rare neoplasm, and account for approximately $0.1 \%-0.2 \%$ of all pituitary neoplasm. ${ }^{[1]}$ Pituitary carcinoma is an extremely rare and typically carry very poor prognosis. For confirmation of diagnosis of pituitary carcinoma, which require demonstration of the presence of metastases, which may develop due to malignant transformation of preexisting benign pituitary adenoma after a varied latency period, ranging from few months to many years. ${ }^{[2]}$ 

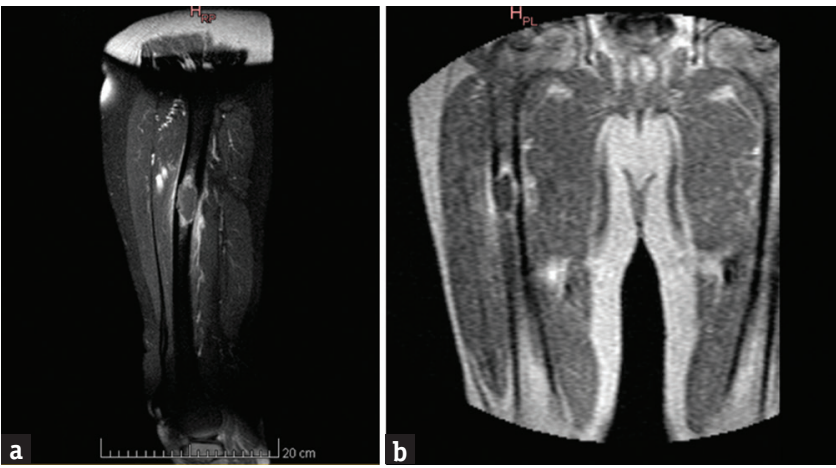

Figure 2: $(\mathrm{a}$ and $\mathrm{b})$ Magnetic resonance imaging of the muscle was present, with diaphyseal metastatic lesion

The diagnoses of pituitary carcinomas require presence of the local invasion and also demonstration of systemic metástasis or cerebrospinal metastasis or is necessary. ${ }^{[3]}$ The benign pituitary adenoma can rarely change in its natural course into aggressive tumor, which typically display poor responsive to therapy. Most pituitary carcinomas are usually functional and commonly include adrenocorticotropic hormone (ACTH)-and PRL secreting carcinomas are the commonest. ${ }^{[2]}$ The pathogenesis of malignant transformation is still ill-understood. However, almost all of the pituitary carcinoma cases occur after the diagnosis and treatment of previously present macroadenoma for the few years and long latency period before metástasis, the median period is about 5 years, however, can range from few months to 18 years..$^{[1,4]}$ In addition, the past surgical or radiotherapy may also play an important role in the metastatic spread. ${ }^{[5]}$

Koyama et al. postulated the three pathways for metástasis from the pituitary adenoma are namely hematogeneous spread, surgical site and dissemination within the central nervous system. In hematogeneous spread, the tumor invades dura of the sella and produces metástasis in close vicinity. Surgical site dissemination occurs along the previous surgical tract. Finally, dissemination through cerebrospinal fluid pathways can occur mostly after surgery. In our case, hematogeneous spread was most probable method of metastatic dissemination to the femur. ${ }^{[6]}$

The majority of reported pituitary carcinomas are the hormone-secreting endocrinological tumor and common subtypes include ACTH - producing tumors (42\%), PRL secreting tumors $(33 \%)$, growth hormone tumors $(6 \%)$, gonadotropin producing $(5 \%)$, thyroid stimulating hormone - producing (1\%), and nonfunctioning tumors $(12 \%)$. PRL - producing pituitary carcinomas, such as the case described here, have been reported as the second-most common subtype of pituitary carcinoma.

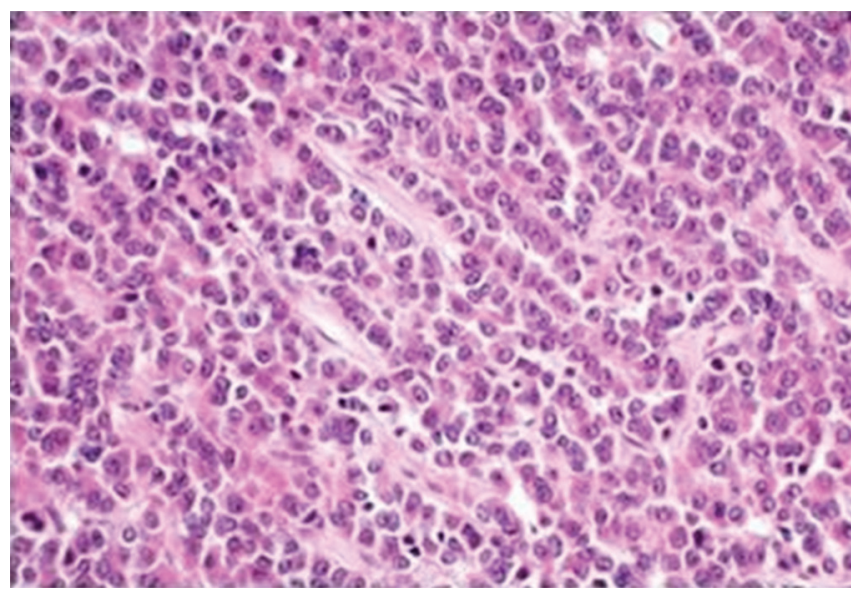

Figure 3: Biopsy was suggestive of metastatic deposit of prolactin secreting pituitary carcinoma

They predominantly occur in males (M: F, 17:9), in middle age (range 14-70 years, mean, 43.6 years), and have a poor prognosis. ${ }^{[7]}$

Lamas et al. observed the most common locations of metastasis from pituitary carcinoma is are extracranial or intracranial and spinal spread. ${ }^{[8]}$

Pituitary carcinoma is presumed to arise from the World Health Organization grade II (atypical) pituitary adenomas. Pituitary carcinoma is defined by metastasis; it is otherwise indistinguishable from atypical pituitary adenomas, which can be considered carcinoma in situ. Pituitary carcinoma is difficult to diagnose and treat. ${ }^{[9]}$

Pernicone et al. noted slight trend toward greater degrees of cytological atypia and a more definite increase in mitotic activity in metastatic lesions in comparison to with primary tumors. ${ }^{[1]}$ Pituitary carcinomas are more aggressive, and usually shows presence of increased MIB-1 labeling index along with p53 staining. ${ }^{[7]}$

The pituitary carcinomas carry extremely poor prognosis, about $<50 \%$ of the cases surviving 1-year after diagnosis. ${ }^{[7,10]}$ The management of pituitary carcinoma is always challenging.

Pernicone et al. observed pituitary carcinoma show a greater tendency toward systemic metastasis than craniospinal metastasis and are associated with poor prognosis. Radiation therapy and dopamine agonist therapy generally provide only palliation. Proliferation indices and p53 expression tend to be higher in metastases than in primary tumors high mitotic and MIB-1 labeling indices as well as p53 immunoreactivity suggest the diagnosis and appear to be of prognostic significance. ${ }^{[1]}$ 
Surgery is usually not curative, but repeated surgical resections of recurrent metastases may appear to prolong the survival in few cases. ${ }^{[1]}$ Radiotherapy is a common adjuvant therapy and used following surgical resection of pituitary carcinoma, however, its role is still debated ${ }^{[11]}$

Dopamine agonists may be considered during early management of PRL secreting producing pituitary carcinomas, but resistance typically develops sooner. ${ }^{[4]}$ Various chemotherapy regimen are tried for treatment especially in patients having systemic metastases. Recently, temozolomide is shown to be effective in suppressing and reducing hormone secretions, the symptoms related to tumor growth, and pituitary carcinoma size. ${ }^{[10]}$ However, the response is, at best, temporary, and further research is necessary to elucidate its role in the management of pituitary carcinomas.

Walker et al. ${ }^{[12]}$ observed PRL-secreting tumors of the pituitary carcinoma almost never metastasize extracranially. Authors could find only 5 cases including their own three cases, showing extracranial metastasis. The first patient was 32-year-old, who underwent repeated transsphenoidal resections, also received radiotherapy and high dose somatostatin analog octreotide and chemotherapy. Nine years after the first diagnosis, a liver biopsy was positive for metastatic liver deposit, and on autopsy metastases were seen in both lungs. Second patient was 48-year treated with external vein pituitary radiotherapy, bromocriptine, transsphenoidal hypophysectomy, and chemotherapy after 15 years developed bone swelling, and biopsia revealed carcinoma cells. The third patient was 48-year-old with hypogonadism underwent transcranial decompression and followed by radiotherapy. At autopsy, tumor was also found in thoracic lymph nodes and lung capillaries. ${ }^{[12]}$

Authors present a case of a pituitary carcinoma in a 73-year-old elderly female was known case of pituitary adenoma with PRL secreting managed surgically and receiving bromocriptine, however, she developed weakness involving one of the lower limbs, MRI showed metastatic deposit in femur. Pituitary carcinoma is a rare disorder. Pituitary adenoma can transform into carcinoma and needs meticulous follow-up endocrinologist, neurosurgeons, and radiologist should be suspicious of such occurrence. She was a known and diagnosed case with a macroprolactinoma in 2007 and developed de novo malignant transformation after many years after diagnosis.

\section{Financial support and sponsorship}

Nil.

\section{Conflicts of interest}

There are no conflicts of interest.

Luis Rafael Moscote-Salazar, Guru Dutta Satyarthee', Willem Guillermo Calderon-Miranda ${ }^{2}$, Jorge Aquino Matus², Alfonso Pacheco-Hernandez, Paulo Cesar Puac-Polanco ${ }^{3}$, Amit Agrawal ${ }^{4}$

Department of Neurosurgert, Universidad de Cartagena, Cartagena de Indias, Colombia, 'Department of Neurosurgery, Neurosciences Centre, All India Institute of Medical Sciences,

New Delhi, ${ }^{4}$ Department of Neurosurgery, Narayna Medical College and Hospital, Nellore, Andhra Pradesh, India, ${ }^{2}$ Department of Radiology, Universidad Nacional Autonoma de Mexico, Ciudad de Mexico, Mexico, ${ }^{3}$ Department of Radiology, University of North Carolina School of Medicine, North Carolina, USA

Address for correspondence: Dr. Luis Rafael Moscote-Salazar, Universidad de Cartagena, Cartagena de Indias, Colombia. E-mail: mineurocirujano@aol.com

\section{REFERENCES}

1. Pernicone PJ, Scheithauer BW, Sebo TJ, Kovacs KT, Horvath E, Young WF Jr., et al. Pituitary carcinoma: A clinicopathologic study of 15 cases. Cancer 1997;79:804-12.

2. Colao A, Ochoa AS, Auriemma RS, Faggiano A, Pivonello R, Lombardi G, et al. Pituitary carcinomas. Front Horm Res 2010;38:94-108

3. Ayuk J, Natarajan G, Geh JI, Mitchell RD, Gittoes NJ. Pituitary carcinoma with a single metastasis causing cervical spinal cord compression. Case report. J Neurosurg Spine 2005;2:349-53.

4. Kaltsas GA, Grossman AB. Malignant pituitary tumours. Pituitary 1998;1:69-81.

5. Gollard R, Kosty M, Cheney C, Copeland B, Bordin G. Prolactin-secreting pituitary carcinoma with implants in the cheek pouch and metastases to the ovaries. A case report and literature review. Cancer 1995;76:1814-20.

6. Koyama J, Ikeda K, Shose Y, Kimura M, Obora Y, Kohmura E, et al. Long-term survival with non-functioning pituitary carcinoma - Case report. Neurol Med Chir (Tokyo) 2007; 47:475-8.

7. Ragel BT, Couldwell WT. Pituitary carcinoma: A review of the literature. Neurosurg Focus 2004;16:E7.

8. Lamas C, Núñez R, García-Uría J, Salas C, Saucedo G, Estrada $\mathrm{J}$, et al. Malignant prolactinoma with multiple bone and pulmonary metastases. Case report. J Neurosurg 2004;101:116-21.

9. Seltzer J, Carmichael JD, Commins D, Liu CS, Omura E, Chang E, et al. Prolactin-secreting pituitary carcinoma with dural metastasis: Diagnosis, treatment, and future directions. World Neurosurg 2016;91:676.e23-8.

10. Arnold PM, Ratnasingam D, O’Neil MF, Johnson PL. Pituitary carcinoma recurrent to the lumbar intradural extramedullary space: Case report. J Spinal Cord Med 2012;35:118-21.

11. McCutcheon IE, Pieper DR, Fuller GN, Benjamin RS, Friend KE, 
Gagel RF, et al. Pituitary carcinoma containing gonadotropins: Treatment by radical excision and cytotoxic chemotherapy: Case report. Neurosurgery 2000;46:1233-9.

12. Walker JD, Grossman A, Anderson JV, Ur E, Trainer PJ, Benn J, et al. Malignant prolactinoma with extracranial metastases: A report of three cases. Clin Endocrinol (Oxf) 1993;38:411-9.

This is an open access article distributed under the terms of the Creative Commons Attribution-NonCommercial-ShareAlike 3.0 License, which allows others to remix, tweak, and build upon the work non-commercially, as long as the author is credited and the new creations are licensed under the identical terms.

\begin{tabular}{|l|l|}
\hline \multicolumn{2}{|c|}{ Access this article online } \\
\hline Quick Response Code: & Website: \\
\hline & www.ruralneuropractice.com \\
\cline { 2 - 2 } & \\
& DOI: \\
\end{tabular}

How to cite this article: Moscote-Salazar LR, Satyarthee GD, Calderon-Miranda WG, Matus JA, Pacheco-Hernandez A, Puac-Polanco PC, et al. Prolactin secreting pituitary carcinoma with extracranial spread presenting with pathological fracture of femur. J Neurosci Rural Pract 2018;9:170-3.

(c) 2018 Journal of Neurosciences in Rural Practice | Published by Wolters Kluwer - Medknow 